\title{
A SOMBRA COMO EXPRESSÃO ARTÍSTICA E ESTÍMULO PROPRIOCEPTIVO PARA A ATRIZ ${ }^{1}$
}

\section{LA SOMBRA COMO EXPRESIÓN ARTÍSTICA Y ESTÍMULO PROPRIOCEPTIVO PARA LA ATRIZ}

\author{
THE SHADOW AS ARTISTIC EXPRESSION AND \\ PROPRIOCEPTIVE STIMULUS FOR THE ACTRIZ
}

\author{
Fabiana Lazzari de Oliveira ${ }^{2}$
}

\begin{abstract}
RESUMO
$\mathrm{O}$ artigo apresenta a sombra como expressão artística e certifica que a práxis com os elementos do Teatro de Sombras é condição sinequa non para a atriz-sombrista adquirir autonomia, aprimorar percepções e aperfeiçoar habilidades psicomotoras para a atuação e para a poiéisis nesta linguagem.
\end{abstract}

PALAVRAS-CHAVE: teatro, teatro de sombras, práxis, poiésis, corpo.

\begin{abstract}
RESUMEN
El artículo presenta la sombra como expresión artística y certifica que la praxis con los elementos del Teatro de Sombras es condición sine qua non para la actriz-sombrista adquirir autonomía, perfeccionar percepciones y perfeccionar habilidades psicomotoras para la actuación y para la poiésis en este lenguaje.
\end{abstract}

PALABRAS CLAVE: teatro, teatro de sombras, práxis, poiésis, cuerpo.

\footnotetext{
${ }^{1}$ Em todas as pesquisas e estudos que perpassei, percebi que a nomenclatura utilizada para o trabalho do/da artista que atua no teatro é a palavra "ator", generalizando a todos e a todas. Esse emprego se deve ao fato do mesmo motivo que se generaliza chamar de "homem" a todos os indivíduos da espécie humana independentemente do sexo. No entanto, a utilização da palavra "homem" tem sustentações na Grécia Antiga, quando os homens de fato eram tratados como o sexo padrão e superiores, as mulheres eram vistas como "um desvio" da grandiosidade masculina. Considero um hábito que reforça o caráter do sexo masculino como dominante na humanidade. Sendo contrária a este hábito, sempre que for me referir às questões que eu pesquiso e que são de minha autoria, empregarei a palavra "atriz" referindo-me tanto ao sexo feminino como ao sexo masculino, pois considero que não existem diferenças entre os gêneros quando relacionados ao trabalho da práxis e da poiésis no teatro de sombras. Nas citações e nas referências das pesquisas e estudos já existentes manterei a palavra que cada um dos autores utilizou: "ator".

2 Doutora e Mestre pelo Programa de Pós-Graduação em Teatro pela Universidade do Estado de Santa Catarina - UDESC. Bacharel em Educação Física - CEFID/UDESC, licenciada em Educação Artística - Habilitação em Artes Cênicas - CEART/UDESC. Sóciafundadora da empresa Fabiana Lazzari Produções, da entreaberta Cia Teatral e do SKIAEspaço da Sombra. Atriz, produtora, arte-educadora e professora no curso de Teatro do CEART/UDESC.
} 


\begin{abstract}
The article presents the shadow as an artistic expression and certifies that the praxis with the elements of the Shadow Theater is a sine qua non condition for the shadow theater actress to acquire autonomy, to improve perceptions and to perfect psychomotor skills for acting and poiesis in this language.
\end{abstract}

KEYWORDS: theater, shadow-theater, praxis, poiesis, body.

$$
* * *
$$

Observar sombras é algo que fazemos desde a infância. Quem nunca tentou ser mais rápido que a própria sombra? Ou esconder a sombra do outro com a sua própria sombra? A sombra é impalpável, incolor, inodora, inaudível e insípida, mas é algo que nos traz sempre muita curiosidade. Muitas vezes também nos traz medo. E é este mistério e encantamento que faz, não só enquanto somos crianças, mas mesmo depois de adultos, apreciarmos a beleza e a mensagem um tanto onírica da sombra.

A sombra surge da fonte de $\mathrm{luz}^{3}$, mas ela aparece apenas no lado escuro do corpo, o lado não iluminado e dali expande-se até encontrar um suporte que irá se fisicalizar. A sombra é, portanto, um volume que se expande infinitamente no espaço. Ela só irá parar se for interceptada por outro corpo. Para que exista a sombra, portanto, são necessários, basicamente, a fonte de luz, um corpo que bloqueie integralmente ou parcialmente a luz e o suporte de projeção na qual irá incidir a sombra ou a ausência integral ou parcial da luminosidade.

No teatro de sombras, a sombra é um duplo, uma projeção da imagem do corpo que intercepta os raios luminosos. A sombra pode ser considerada, também, um simulacro do corpo que intercepta os feixes luminosos quando manipulamos a fonte de luz de forma que a projeção da sombra sofra distorções ou modifique o tamanho do corpo que intercepta os feixes luminosos. Ela tem algumas características, tais como: o tamanho -

\footnotetext{
3 Fonte de luz é todo corpo capaz de emitir luz. O sol, por exemplo, fornece luz desde os primórdios e é uma fonte de luz natural. Ele possui luz suficiente para gerar sombras e até criar narrativas de acordo com o posicionamento dos corpos (animais, plantas, seres humanos), porém não conseguimos controlá-lo, sendo preciso adequar-se ao que ele nos oferece. Nos teatros de sombras tradicionais, há indícios de que se utilizava a luz do sol para contar histórias, posicionando a tela em locais estratégicos. O homem pré-histórico poderia usufruir da luz da fogueira para projetar sombras nas paredes das cavernas e contar ao grupo suas caçadas, e neste caso, o controle seria apenas acender e apagar a fonte de luz. Com o passar do tempo, novos recursos foram criados e continuam evoluindo.
} 
aumenta ao aproximar o objeto da fonte de luz e diminui ao se afastar dela (uma sombra nunca poderá ser menor que o objeto que a produz); a elasticidade - pode distorcer-se, alterando suas proporções, e a sobreposição, quando várias sombras se projetam sobre o mesmo suporte, o resultado final é a mescla delas (as sombras de maior tamanho ocultam as menores) (CASTILHO, 2004).

A matéria expressiva sobre a qual se funda o teatro de sombras é a sombra. A sombra ganha vida quando é projetada e pode ser transformada, assumir papéis distintos:

As sombras evocam a fragilidade, o cômico da vida, o carinho pelos destinos que podem se quebrar como cascas de ovos. Ao mesmo tempo elas contêm a força da liberdade, do humor, da ironia, do riso. Elas deslizam entre as grades, escapando dos torturadores, dos atormentados. Elas brilham, luzes negras por um mundo diferente (LESCOT, 2005, p.10)!

A sombra é poesia, é descoberta, é conhecimento, é experimentação, é expressão. A grandeza do universo da sombra produz, a cada experimentação, novas possibilidades. Acredito que pensar o teatro de sombras, é também pensar lúdico. É um mundo de encantamento visual, produto do jogo da luz e das formas em constante relação com o uso de nosso corpo. As sombras são misteriosas e as considero ideais para criar atmosferas de sonhos e poesia, assim como aprimorar as nossas percepções que ficam esquecidas no nosso dia-a-dia.

O Teatro de Sombras tem se transformado consideravelmente nos últimos quarenta anos e com essas mudanças a atriz conseguiu romper algumas barreiras, entre elas: deixar de fazer a projeção das silhuetas somente atrás da tela e utilizar o seu próprio corpo para as projeções. O corpo humano começou a fazer parte da cena do teatro de sombras quando surgiram as lâmpadas puntiformes ${ }^{4}$, pelas quais se deu maior nitidez e acuidade à imagem, surgindo assim novas técnicas e estéticas ligadas à sombra corporal. O corpo pode estar à frente ou atrás do suporte de projeção, em qualquer lugar do espaço cênico, com fontes luminosas fixas ou móveis.

\footnotetext{
${ }_{4}^{4}$ Mais informações sobre fontes de luz no link do artigo "A luz - elemento primordial no teatro de sombras", escrito por mim e pelo professor Doutor Valmor Beltrame, na Revista Urdimento $\mathrm{n}^{\circ} 23$, ano 2014:

http://www.revistas.udesc.br/index.php/urdimento/article/view/1414573102232014017
} 
Com essas modificações contemporâneas, surgem muitas hipóteses para a dramaturgia e consequentemente um aumento de possibilidades de uso dos elementos que compõem o teatro de sombras. É um território aberto, um lugar de investigação e experimentações. Assim, nascem novas possibilidades para a criação cênica.

Como estamos falando de Teatro de Sombras um dos elementos fundamentais, especificamente por ser teatro, é a atriz-sombrista, responsável pela atuação com o corpo/objeto/boneco/figura que dará vida à sombra. As características intrínsecas à sombra, como um fenômeno observável, tornam o trabalho desta atriz mais complexo no processo de animação da sombra, ou, no seu uso como um objeto de apreciação poética e estética.

Para chegar na criação poiética é importante entender a lógica do uso dos elementos que compõem o teatro de sombras. A atriz estará se movimentando e se deslocando pelo espaço para projetar as imagens das sombras, estará movimentando-se para manipular os objetos, silhuetas, fontes de luz e o próprio corpo - os índices de profundidade estarão agindo, pois conforme o atriz-sombrista se movimenta e faz o seu trabalho de interpretação, ele será influenciado pela perspectiva dinâmica, paralaxe de movimento e movimentos de rotação. Ela precisa ter uma capacidade sensorial muito ativa e com isso podemos dizer que Teatro de Sombras é percepção. O corpo deve se adaptar ao escuro. A atriz tem que conseguir enxergar a sombra a partir de uma visão periférica. E para isso é preciso vivenciar experimentando na prática. Muitas vezes, o que pensamos, acontece de forma diferente ou até não acontece quando não conhecemos os princípios de movimentos com a fonte de luz e com o corpo no espaçosombra, aquele espaço "entre" a fonte luminosa e o suporte de projeção na qual a imagem da sombra se fisicaliza. Sendo assim, nas minhas pesquisas dou ênfase às relações e experimentações que ligam a atriz à silhueta, à sombra de seu corpo, à sua voz, ao seu corpo e como se estabelecem essas relações no processo de criação no Teatro de Sombras considerando os 
elementos: espaço, iluminação, dramaturgia e cenografia ${ }^{5}$. Essas relações vêm a partir do corpo da atriz, pois é o corpo que tem relação direta com esses elementos. É a partir dele que a atriz consegue ter as percepções em suas diversas vertentes entre elas: a percepção visual, a percepção espacial, a percepção cinestésica e a propriocepção. O corpo vai adquiri-las ou aperfeiçoa-las trabalhando com a práxis e com a poiésis ${ }^{6}$.

\section{Treinamento como práxis e treinamento como poiésis}

Mas o que é a práxis e a poiésis neste contexto? O treinamento como práxis utiliza-se de procedimentos predeterminados e seus objetivos estabelecidos de diversos modos: "ele seria um meio que serviria a uma finalidade” (BONFITTO, 2009, p. 38); já no treinamento como poiésis, o objetivo mais importante seria de "criar as condições para que os materiais emerjam, para que eles possam vir à tona, os quais podem ser ulteriormente desenvolvidos pelos atores" (idem, 2009, p. 38). Matteo Bonfitto, apresentaos como dois modos de conceber e acionar o treinamento do ator: um treinamento estruturado e um treinamento não-estruturado. Em analogia aos meus pensamentos e conhecimentos sobre treinamento corporal, assim como as vivências com teatro de sombras, divido estas conceituações em dois pontos no teatro de sombras: a prática corporal e técnica para a atuação no teatro de sombras, isto é, o desempenho individual com os elementos técnicos do teatro de sombras (relações da atriz-sombrista com o escuro, com a fonte de luz, com as silhuetas, com o corpo e com o suporte de projeção) no espaço cênico; e o trabalho de criação cênica, no qual a atriz está acostumada e imbricada com todos os elementos acima citados para de maneira orgânica utilizá-los da melhor forma possível no processo criativo do espetáculo. Portanto, no caso do teatro de sombras vivenciado e experimentado por mim, percebo que tanto o treinamento como práxis, com a aplicação da parte técnica do teatro de sombras (como por exemplo, saber

\footnotetext{
${ }^{5}$ Essas relações são discutidas na dissertação "Alumbramentos de um corpo em sombras: o ator na Cia Teatro Lumbra de Animação (2011), UDESC, Florianópolis: 2011.

${ }_{6}$ Os conceitos e reflexões inseridos neste artigo são partes da minha tese "Da prática pedagógica a atuação no Teatro de Sombras: um caminho na busca do corpo-sombra", UDESC, Florianópolis, 2018.
} 
manusear os elementos que fazem parte da linguagem); como o treinamento como poiésis, com a exploração dos princípios apreendidos do treinamento como práxis dando vazão a criação cênica, são utilizados no trabalho com teatro de sombras. E eles fazem entendermos que corpo é esse trabalhado para a criação nesta linguagem e quais são as nossas habilidades adquiridas e/ou aperfeiçoadas nos processos.

Quem se dispõe a aprender e trabalhar com o teatro de sombras deve descobrir pessoalmente que:

A sombra além de se tornar visível, perceptível, evidente, a nossa realidade física através da sua representação sintética, a sombra tem também o poder de encarnar, inclusive imaterialmente forças e energias. Algo ou alguém pode habitála, e por isso ela se oferece generosamente ao encontro conosco: para ser "animada". Na sombra, nós projetamos não só os contornos de nosso corpo, nossa figura, mas também nossa vitalidade ou, podemos dizer, nossa alma. É importante que quem se dispõe a aprender o teatro de sombras descubra tudo isso pessoalmente (MONTECCHI, 2015, p. 55).

O pensamento de Montecchi se aproxima, em alguns aspectos, ao conceito de sombra utilizado por Jung (2008, p. 229). Jung chamou de "sombra" determinado aspecto da personalidade inconsciente referindo-se a um fator relativamente definido, mas chamando atenção para o seguinte:

Por vezes, tudo que o ego desconhece mistura-se à sombra, incluindo as mais valiosas e nobres forças. [...]. Se a figura da sombra contém forças vitais e positivas, devemos assimilá-las na nossa experiência ativa, e não as reprimir. Cabe ao ego renunciar ao seu orgulho e vaidade para viver plenamente o que parece sombrio e negativo, mas que na realidade pode não o ser. Tudo isso exige, às vezes, um sacrifício tão heroico quanto o de dominar uma paixão - mas em sentido oposto (VON FRANZ apud JUNG, 2008, p. 230).

Sendo assim, trabalhar com teatro de sombras pode ser uma forma de conhecermos e pesquisarmos a sombra desvendando as forças vitais (o corpo, a mente e o espírito - a alma da sombra), transformando-a em energias para a atuação com a sombra como expressão artística no espaço cênico.

Pensar a energia é primordial para se refletir as necessidades desta atriz. Segundo Barba (1994, p. 84), em seus estudos da antropologia teatral, a palavra grega enérgheia quer dizer estar pronto para a ação, a ponto de produzir trabalho:

No instante que precede a ação, quando toda a força necessária se encontra pronta para ser liberada no espaço, mas como que suspensa e ainda presa ao punho, o ator experimenta a sua energia na forma de sats, preparação dinâmica. [...] O sats 
compromete o corpo inteiro. [...] Numa sequência de ações, é uma pequena descarga de energia que faz mudar o curso e a intensidade da ação ou a suspende improvisadamente. É um momento de transição que desemboca numa nova postura bem precisa uma mudança de tonicidade do corpo inteiro. (BARBA, 1994, p. 84).

A atriz-sombrista faz transições para novas posturas, em função dos movimentos e dos deslocamentos espaciais no escuro ao mesmo tempo em que trabalha com seu corpo oculto ou visível ao espectador. Fávero (apud OLIVEIRA, 2011, p. 142) afirma que no teatro de sombras o ator deve estar em "estado de vigília" constante e enfatiza que a posição "base" do ator é primordial para o seu desempenho em cena. Essa base, fundamental para Fávero, é análoga ao que Ferracini (2003, p. 147) conceitua em suas pesquisas sobre o trabalho do ator e que eu considero fundamental em qualquer atuação: "é uma postura especial dos pés e quadril determinando uma base de sustentação diferente da cotidiana”. A descoberta da base de sustentação do corpo possibilita a segurança para posições extracotidianas, e uma liberdade para a coluna vertebral, que assim, poderá soltar-se sobre uma base segura e fixa.

O trabalho de Barba em relação ao treinamento do ator consiste em superar os vícios ligados à corporeidade cotidiana, aos maneirismos e a corporeidade natural. E isso vem ao encontro da necessidade da atriz no teatro de sombras, pois desde o início do trabalho necessita aprender a trabalhar no escuro e com as tantas outras características presentes nas técnicas do teatro de sombras. A escuridão para os nossos olhos não é tão adaptável como a claridade (OLIVEIRA, 2011, p. 78). Para Barba,

\footnotetext{
A profissão do ator inicia-se geralmente com a assimilação de uma bagagem técnica que se personaliza. O conhecimento dos princípios que governam o bios cênico permite algo mais: aprender a aprender [...] é a condição de dominar o próprio saber técnico e não ser dominado por ele (BARBA, 1994, p. 24).
}

Ele nos diz ainda que vamos encontrar uma anatomia especial para o ator, isto é "seu corpo extracotidiano", um "novo corpo", onde a presença física e mental do ator modela-se diferentemente do cotidiano. O corpo age com outra qualidade de energia. A energia do ator é a força dos músculos e nervos, a mesma existente em qualquer ser vivo, a questão está em como ela é utilizada no contexto específico: no teatro. No dia-a-dia, geralmente há 
uma reserva de energia, que não são utilizadas no cotidiano e que atores/atrizes utilizarão na cena.

A atriz no teatro de sombras está sempre experimentando e descobrindo novas possibilidades, está sempre precisando "aprender a aprender" e acrescento "aprender a desaprender para (re)aprender". É preciso estar aberta às mudanças. Para desaprender é preciso deixar para trás o que nos acompanhou durante toda nossa vida. Não se trata de renunciar ao que já se aprendeu, mas selecionar o que vale e o que não vale para o que estamos fazendo. É preciso ter a mente aberta a novas experiências, a novos pontos de vista e a novos conhecimentos. Assim poderemos voltar a ser crianças curiosas deixando de lado os prejuízos e a rigidez de se ter um único ponto de vista.

Esse aprender a aprender no teatro de sombras começa no primeiro momento de contato com esta linguagem que na pedagogia para ensinar teatro de sombras chamo de sensibilização, pois o tempo e o espaço da sombra são diferentes do nosso cotidiano. É preciso, primeiramente conhecer a sombra natural ${ }^{7}$ (foto 1 ) para depois trabalharmos com a sombra artística $^{8}$ (foto 2$)$.



Foto 2 - Sombra natural das folhas e galhos de uma árvore a luz do sol

Acervo: Fabiana Lazzari

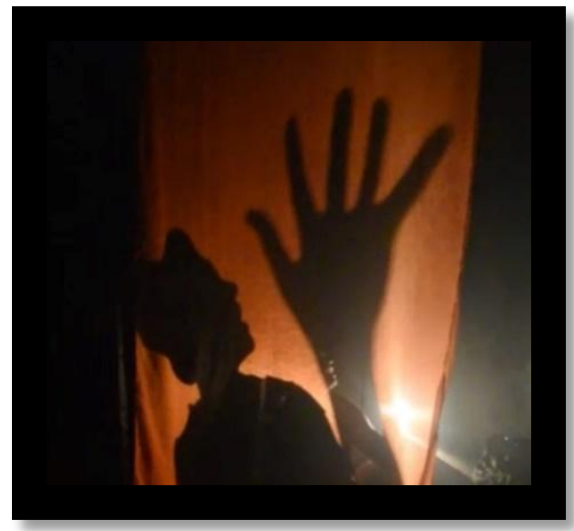

Foto 1 - Sombra artística Intervenção de luzes e Sombras

(2018)

\footnotetext{
7 Sombra natural é a sombra do dia-a-dia, que é projetada em todos os momentos em que estamos com o corpo na luz, que é vista, mas pela qual não temos a intenção de mostrar ao outro algo diferente dela.

8Sombra artística é a sombra que se destaca da atriz e que troca informações com o outro, é a sombra que se torna criatura com formas diferentes dando possibilidades de troca imagética com o outro.
} 
A primeira premissa é conhecer e entender o que é a sombra, de onde ela vem e o que ela suscita quando a vemos. As dinâmicas de sensibilização ${ }^{9}$ com a sombra, para reencontrá-la ${ }^{10}$ e reconhecê-la são fundamentais no início de um trabalho com teatro de sombras. A sensibilização envolve o conhecimento filosófico ${ }^{11}$ e científico $^{12}$ do que é a sombra. Ajuda a desvendar os seus significados metafóricos e aspectos físicos e psicológicos. É um momento da descoberta da sombra e de entender as diferenças de sombra natural e sombra artística. A sensibilização compõese de dinâmicas realizadas primeiramente no escuro, geralmente de olhos vendados, tendo o contato com os outros sentidos corporais que não sejam a visão: o tato, o paladar, o olfato e a audição, utilizando-se de estímulos para cada um deles. Esta prerrogativa de conhecer a sombra e o escuro tem uma grande relevância, pois inspira, no trabalho, o cultivo de questões tais como: Como percebemos o escuro? Com que órgãos sensoriais percebemos o escuro? Como funciona o olho, segundo o parecer de cada um, quando percebemos o escuro? Como age a pele quando percebemos o escuro? Quais sensações sentiríamos se pudéssemos tocar o escuro? Se pudéssemos fabricar o escuro, de que material seria? Que posturas o nosso corpo pode representar o escuro? Se o escuro produzisse sons? Quantos e quais seriam? Se a escuridão tivesse sabor? Qual seria? A escuridão tem forma? Se a escuridão fosse um animal? Qual seria? Quais as cores da escuridão? Existe diferença entre o escuro e a sombra? Essas provocações, visam despertar novas percepções e propriocepções que expandam a capacidade de prestar atenção ao fenômeno

\footnotetext{
9 Entendo sensibilização como o ato de sensibilizar a si mesmo e/ou a outros envolvidos direta e/ou indiretamente na situação definida previamente, neste caso conhecer a sombra. 10 Reencontrá-la porque desde a infância temos contato com a nossa sombra, porém em muitos casos nem sabemos quem ela é e muito menos percebemos que ela está sempre conosco e reconhece-la porque a vemos, mas não damos valor ao potencial expressivo que ela tem.

${ }^{11}$ Reflexão de questões subjetivas sem buscar comprovações, como por exemplo: escutar o que a sombra tem a dizer, falar com ela e perceber o que ela responde. As respostas vêm com conclusões hipotéticas.

12 Testamos e verificamos algumas teorias sobre a sombra comprovando a veracidade ou a falsidade das mesmas como por exemplo a proporção de tamanho que a sombra pode variar. A busca da pedagogia do teatro de sombras constrói um conhecimento científico, e o fato de que a sistematização é uma característica do trabalho teatral com sombras colabora para a criação de uma base teórica e registro de comprovações a partir de experimentações atestando ou não a sua veracidade.
} 
da escuridão. Durante esse processo de descobertas, cada um de nós traz as próprias contribuições, de acordo com as vivências culturais, isto é, trazendo o valor simbólico atribuído à escuridão, de acordo com a experiência cultural de cada um. Logo após, quando abrimos os olhos, percebemos a diferença de estar no espaço escuro utilizando o sentido da visão. A visão amplia-se e as percepções do espaço dilatam-se. É o trabalho de adaptação à escuridão.

A partir do momento em que estamos adaptados à escuridão, podese acionar uma fonte de luz, e então, termos o contato com a nossa sombra, sombra do próprio corpo, conseguindo percebê-la deitada no chão, ou em pé, projetada nos suportes/anteparos existentes no espaço. Desta forma, somos estimulados a conhecer o que é a "massa cinzenta13" que vemos projetada e que está sempre conosco - a sombra natural: o que é e quem representa a sombra? Como ela age? É possível tocá-la? E ouvi-la? Será que ela me ouve? Acaricie a sua sombra, contorne-a com suas mãos, escute a sua sombra, o que ela tem a dizer? Converse com sua sombra, conte um segredo a ela. Qual é o menor tamanho que ela fica? E o maior? Consigo fazê-la desaparecer? Se desvencilhar do meu corpo? O que é o sentir? O que é o ver e o que é o perceber? Entre questionamentos, sensações e percepções estamos além de reencontrar a nossa sombra, estamos também conhecendo mais um pouco das possibilidades do nosso corpo psicofísico.

As sensibilizações têm como função, primeira e principal, a percepção do escuro, da luz e da sombra que fazem parte de nosso dia-a-dia e que estarão presentes no teatro de sombras de forma diferenciada da cotidiana. Elas ajudam a ativar a capacidade de prestar atenção ao fenômeno da escuridão e da luz, assim como provocar os outros sentidos (tato, olfato, paladar, audição) mostrando que eles são tão importantes quanto a visão. Nós estamos imersos na luz e isso nos torna acomodados para com os outros sentidos, muitas vezes deixamos de experimentar uma certa comida, por exemplo, em função da aparência que ela nos mostra.

\footnotetext{
13 Massa cinzenta é a sombra projetada visível em algum suporte ou superfície de projeção. Esta expressão é comumente utilizada pelo professor Paulo Balardim em suas aulas de teatro de sombras, e indica que podemos modifica-la dando formas diferenciadas como utilizamos a massa de modelar.
} 
Merleau-Ponty (1999), em sua Fenomenologia da Percepção, enuncia que, para compreender a percepção, é fundamental a noção da sensação. A sensação é compreendida em movimento: "a cor, antes de ser vista, anunciase então pela experiência de certa atitude de corpo que só convém a ela e com determinada precisão" (MERLEAU-PONTY, 1999, p. 284). A percepção está relacionada à atitude corpórea, e assim como Ponty, acredito que a apreensão dos sentidos se faz pelo corpo: "se se faz um estímulo luminoso crescer pouco a pouco a partir de um valor subliminar, primeiramente se experimenta uma certa disposição do corpo e, repentinamente, a sensação continua e se propaga no domínio visual" (MERLEAU-PONTY, 1999, p. 284). Quem está sentindo "é uma potência que co-nasce em um certo meio de existência e se sincroniza com ele" (idem, p. 285). As vivências, primeiramente, no escuro e depois com a luz, fazem com que rememoremos a partir do corpo as sensações de experiências vividas no mundo. Aconteceu em oficinas ministradas por mim, de participantes adultos, por exemplo, relembrarem seus momentos da infância quando brincavam à luz de vela, quando andavam de bicicleta e passavam por um poste de luz parecia que havia alguém os seguindo, pois viam a sombra em movimento devido à projeção da mesma no chão e, como a bicicleta estava em movimento, a sombra também era vista em movimento. As sombras podem evocar lembranças e opiniões distintas.

Após descobrir e conhecer a "matéria expressiva" do teatro de sombras, é preciso conhecer os seus recursos técnicos e entender a lógica do seu funcionamento para praticar com autonomia e conseguir criar composições de imagens com as sombras para as cenas. Por exemplo: eu quero uma sombra que preencha todo o suporte de projeção; sei que o corpo que terá sua sombra projetada deve ficar mais próximo da fonte de luz e afastado do suporte. Para o teatro de sombras acontecer é preciso aprender o funcionamento dos recursos e conseguir, a partir dessa percepção fazer movimentos que criem composições com a imagem da sombra no suporte de projeção, trabalhando assim com a poiésis (próxima etapa). No treinamento como práxis, entende-se a lógica do movimento do corpo no espaço de criação 
da sombra, para projeção da imagem da sombra; entender a sombra como instrumento de representação teatral; entender qual é o espaço da sombra, que é tridimensional; qual é o espaço da fisicalidade da sombra, que é bidimensional; qual é a origem da sombra artística, como atuar com a sombra e entender qual é o papel da atriz-sombrista nesta atuação.

A percepção do uso da tridimensionalidade do espaço entre a fonte luminosa e o suporte de projeção; as modificações do tamanho, forma, posição e velocidade da sombra que são visualizadas de acordo com a manipulação da fonte de luz e do corpo que está inserido na tridimensionalidade do espaço entre a fonte de luz e o suporte - caminhadas dentro deste espaço treinando os deslocamentos possíveis (lateralmente, verticalmente e diagonalmente), para perceber as mudanças e diferenças produzidas adquirindo uma percepção corporal e observando como será a velocidade, as transformações e a nitidez da sua sombra são práxis necessárias para a autonomia na criação poiética. Deve-se entender o que acontece em cada situação para que o corpo apreenda os fundamentos. Ter o domínio de como podemos atuar com e nas três dimensões existentes. Os movimentos e deslocamentos devem ser lentos, trabalhados devagar, para que consigamos visualizar todos os detalhes da imagem da sombra produzida. É preciso fundamentar essa gramática baseada em suas particularidades, para se ter uma autonomia artística.

\section{Poiésis no Teatro de Sombras}

Na criação, umas das minhas referências teóricas é Fayga Ostrower:

Criar é, basicamente, formar. É poder dar uma forma a algo novo. Em qualquer que seja o campo de atividade, trata-se, nesse "novo", de novas coerências que se estabelecem para a mente humana, fenômenos relacionados de modo novo e compreendidos em termos novos. $\mathrm{O}$ ato criador abrange, portanto, a capacidade de compreender; e esta, por sua vez, a de relacionar, ordenar, configurar, significar (OSTROWER, 2012, p. 9).

A criação dos espetáculos de que participo segue nesse caminho, a compreensão do que se quer fazer para poder relacionar, ordenar, configurar e significar os detalhes de cada um deles:

Quando se configura algo e se o define, surgem novas alternativas. Essa visão nos permite entender que o processo de criar incorpora um princípio dialético. É um 
processo contínuo que se regenera por si mesmo e onde o ampliar e o delimitar representam aspectos concomitantes, aspectos que se encontram em oposição e tensa unificação. A cada etapa, o delimitar participa do ampliar. Há um fechamento, uma absorção de circunstâncias anteriores, e, a partir do que anteriormente fora definido e delimitado, dá-se uma nova abertura. Da definição que ocorreu, nascem as possibilidades de diversificação. Cada decisão que se toma representa assim um ponto de partida, num processo de transformação que está sempre recriando o impulso que o criou (OSTROWER, 2012, p. 26).

Os processos criativos são contínuos, estamos sempre nos recriando, nos proporcionando estímulos novos para gerar mudanças na criação. No teatro de sombras, para criar é preciso uma práxis exaustiva com os fundamentos técnicos que fazem parte da linguagem e substancialmente utilizando-os no processo de poiésis.

A sombra existe no instante em que é fruída, no instante em que a atriz-sombrista a recria para quem veio encontrá-la: o espectador. A atrizsombrista deve ser a energia motriz (força que movimenta alguma máquina ou objeto) e a energia vital. Ela é a criadora de tudo o que ocorre. Essas energias acontecem em sintonia e em continuum durante a atuação, quando o trabalho da atriz-sombrista, antes e durante o processo de criação do espetáculo, for bem conduzido. Se, às vezes, a atriz-sombrista parece estar ausente, ela está, na verdade, apenas oculta. A sua energia, porém, é passada para todos os elementos do espetáculo. Por isso, é importante o aprendizado para canalizá-la, direcionando-a para a silhueta/objeto ou silhueta/corpo e, dessa, para a sombra. A atriz deve entender que há uma diferença entre o direcionamento de energias para essas duas silhuetas: quando a atriz-sombrista está direcionando-a para a silhueta/objeto ela deverá saber se anular, determinando uma orientação nos significados da sua presença, a fim de que a sombra desta silhueta/objeto se destaque; e quando a atriz-sombrista está direcionando a energia para a silhueta/corpo ela terá que trabalhar a sua presença, mas não simplesmente a do seu corpo e sim a do corpo da sua sombra, que está sendo projetada e que é a personagem principal, nesse caso. Existe uma "dupla presença" da atriz em cena: no espaço da sombra e na imagem virtual da sombra no suporte de projeção. O espaço da sombra é tridimensional e conforme a atriz 
movimenta-se e atua, a imagem da sombra finalizada no suporte de projeção também se movimenta e se modifica. É necessária uma percepção dilatada.

A percepção dilatada nos faz chegar ao corpo-sombra. Corpo-sombra é uma expressão criada e conceituada por $\operatorname{mim}^{14}$ a partir da práxise da poiésisno teatro de sombras e consiste no estado de atenção multifocal da atriz na sua corporeidade e no mundo percebido, produzindo autonomia e dançabilidade no espaço-tempo de atuação no teatro de sombras.

Dentre as percepções que são aprimoradas para se estar em corposombra no teatro de sombras contemporâneo estão: a percepção visual, a percepção auditiva, a percepção háptica, a percepção do espaço, a percepção do formato, a percepção vestibular, a percepção térmica, a propriocepção, a percepção de tempo, a percepção cinestésica, a velocidade de ação e reação, a coordenação, o equilíbrio, a lateralidade, o grau de precisão de movimentos. É imprescindível termos consciência de que a sombra é tridimensional e que quando estamos dentro do espaço-sombra ela ali também estará. O corpo da atriz-sombrista ou a silhueta/figura/boneco/objeto estará em afecção com a sombra, produzindo uma imagem no suporte de projeção e fruída na sua superfície.

Para animar a sombra corporal e todas as suas variantes com as silhuetas/figuras/bonecos/objetos, requer-se uma atitude do uso do corpo, e todas as técnicas que são utilizadas se baseiam neste corpo e nas capacidades da atriz-sombrista para ter a postura adequada perante cada possibilidade. A atuação acontece com o corpo todo, mesmo não estando o corpo inteiro no espaço-sombra. A atriz-sombrista deverá estar sempre em corpo-sombra durante a atuação. E para estar neste estado de atenção reitero que é imprescindível praticar, individualmente e em conjunto. Por meio do treinamento como práxis e treinamento como poiésis adquirirá habilidades e/ou fortalecerá as habilidades motoras e psicomotoras acima descritas. Praticar o corpo-sombra é uma excelente forma de conquistar

\footnotetext{
${ }_{14}$ Mais informações sobre o conceito corpo-sombra na tese "Da Prática pedagógica a atuação no Teatro de Sombras: um caminho na busca do corpo-sombra", UDESC, Florianópolis, 2018.
} 
novas valências e/ou fortalecer habilidades já existentes. Considero o corposombra um treinamento proprioceptivo para a atriz.

A atriz-sombrista necessita constantemente lidar com a sensibilidade da propriocepção. Esta auxilia a atriz-sombrista antes de tomar resoluções em determinadas ações no escuro: “diz respeito à discriminação entre intensidades ou níveis de um estímulo ou sinal" (MAGILL, 2000, p. 58). No caso do teatro de sombras, a atriz necessita constantemente laborar com essa sensibilidade. No escuro, ela precisa, por exemplo, perceber a hora em que a outra atriz-sombrista inicia a cena acionando o dimmer do dispositivo de luz, isto é, a acuidade visual dessa atriz é um feedback proprioceptivo para o seu movimento. A propriocepção e a visão são duas fontes importantes de feedback envolvidas no controle do movimento. O feedback proprioceptivo fornece informações de precisão espacial importantes no decorrer de um movimento (MAGILL, 2000). O sistema nervoso está continuamente realimentando o centro de controle do movimento com informações proprioceptivas, o que permite a atualização das posições dos membros e, consequentemente, que a pessoa faça os ajustes necessários à trajetória correta dos membros (idem, 2000, p.58). Portanto, uma das funções importantes do feedback proprioceptivo é o grau de precisão nos movimentos, o que considero ser fundamental para a atriz no teatro de sombras e que também irá potencializar o trabalho da atriz em qualquer atuação.

É preciso ativar os canais de percepção. A cinestesia, que tem a ver com as percepções dos movimentos corporais/musculares, isto é, a propriocepção já comentada acima; e a sinestesia, que tem a ver com o que é "sensorial", que mistura diferentes sentidos humanos, que usa a inteligência sensório-cinestésica. Normalmente temos um dos canais como preferência: o visual, o auditivo ou o cinestésico, mas no teatro de sombras é importante equilibrá-los principalmente porque a maioria do trabalho é no escuro. Entre as características dessa inteligência sensório-cinestésica, segundo Howard 
Gardner $^{15}$ (1994, p. 161), está a capacidade de usar o próprio corpo de maneiras altamente diferenciadas e hábeis para propósitos expressivos, assim como a capacidade de trabalhar habilmente com objetos, tanto os que envolvem movimentos motores finos dos dedos e mãos quanto os que exploram movimentos motores mais amplos do corpo. Ambas as capacidades necessárias para o trabalho da atriz no teatro de sombras contemporâneo, que se utiliza de atuação de objetos, fontes de luz, silhuetas/figuras/objetos/bonecos/corpos.

O processo de criação no teatro de sombras é diferente das outras formas teatrais: os ensaios não têm como acontecer sem os equipamentos mínimos, o teatro de sombras está ligado ao escuro, à presença das fontes de luz e aos suportes de projeção formando um espaço-sombra para a atuação. Essas características juntamente com as principais transformações que aconteceram no teatro de sombras e que modificaram a sua forma do fazer nas últimas décadas, tais como: a ruptura do espaço tradicional, abrangendo agora todo o espaço cênico; a descoberta da luz elétrica viabilizando que a atriz utilizasse o seu próprio corpo em cena projetando a sua sombra em qualquer lugar do espaço cênico tornando todos os seus movimentos visíveis; o monitoramento dimmerizado das fontes luminosas controlando a intensidade, qualidade e quantidade de luz no espaço; a sombra tornou-se tridimensional e possível de ser fisicalizada em qualquer suporte de projeção, diferentemente de quando ela era apenas obtida pelo contato direto da silhueta com o suporte (tela); e assim as materialidades para o suporte de projeção podem ser variadas e não mais apenas um tecido translúcido. Enfim, estas transformações, modificações e inovações possibilitam múltiplas e diferentes criações poéticase deram-me a oportunidade de estar em corpo-sombra, conscientizar-me sobre ele e defini-lo tecnicamente. Existem ainda muitas curiosidades e possibilidades a serem estudadas. Que

\footnotetext{
15 Psicólogo cognitivo e educacional estado-unidense, ligado à Universidade de Harvard e conhecido em especial por sua teoria das inteligências múltiplas. Segundo este autor, no seu livro Estruturas da Mente (1994) existem nove dimensões de inteligência: a linguística, a musical, a lógica/matemática, a visual/espacial, a corporal/cinestésica, a interpessoal, a intrapessoal, a naturalista e a existencialista. De uma forma geral utilizamos todas no teatro e seria uma outra pesquisa explorar e entender cada uma delas na prática com teatro de sombras.
} 
outros artistas e professores também se aproximem e tragam suas incertezas e descobertas. $\mathrm{O}$ teatro de sombras está aberto para o estudo do passado e para as novas descobertas e transformações. É uma linguagem que propicia uma experiência sinequa non para o autoconhecimento e para o aprofundamento na atuação de atrizes e atores pois a sombra, como expressão artística, sendo a protagonista, propõe outra condição de produzir e executar concepções de ideias para que ela possa agir e expressar-se.

$$
* * *
$$

\section{REFERÊNCIAS}

BARBA. E. A Canoa de Papel: Tratado de Antropologia Teatral. São Paulo: Editora HUCITEC, 1994.

BONFITTO, Matteo. A Cinética do Invisível: Processos de Atuação no Teatro de Peter Brook. São Paulo: Perspectiva, Fapesp, 2009.

CASATI, Roberto. A Descoberta da Sombra: de Platão a Galileu, a história de um enigma que fascina a humanidade. São Paulo: Companhia das Letras, 2001.

CASTILLO, Domingo. Hágase La sombra! In: La sombra desvelada: um viaje por el teatro de sombras.AYUSO, Adolfo (coord). $1^{\text {a }}$ Edición. Zaragoza: Imprenta Provincial de Zaragoza, 2004.

FERRACINI, Renato. A arte de não interpretar como poesia corpórea do ator. Campinas: Editora da Unicamp, 2003.

GARDNER, Howard. As Artes e o Desenvolvimento Humano. Trad. Sandra Costa.Porto Alegre: Editora Artes Médicas Sul Ltda., 1994.

JUNG, Carl. G. O Homem e seus Símbolos. Trad. Maria Lúcia Pinho. Rio de Janeiro: Nova Fronteira, 2008.

LESCOT, Jean Pierre. Poesia e Amor no Teatro de Sombras. Tradução ValmorBeltrame. In: Teatro de Sombras: técnica e linguagem. BELTRAME, Valmor (org.) Florianópolis: UDESC, 2005. 
MAGILL, Richard. A. Aprendizagem Motora - Conceitos e Aplicações. Trad. Aracy Mendes da Costa; revisão técnica José Fernando Bittencourt Lomônaco. São Paulo: Edgard Blucher, $5^{\mathrm{a}}$ ed., 2000.

MERLEAU-PONTY, Maurice. Fenomenologia da Percepção. Trad. Carlos Alberto Ribeiro de Moura. $2^{\text {a }}$ edição. São Paulo: Martins Fontes, 1999.

MONTECCHI, Fabrizio. Instruir e/ou Educar - Por uma pedagogia do Teatro de Sombras. In: Móin-Móin: Revista de Estudos sobre o Teatro de Formas Animadas. Jaraguá do Sul: SCAR/UDESC, ano 11, v. 14, 2015. OLIVEIRA, Fabiana Lazzari de. Alumbramentos de um Corpo em Sombras: o ator da Companhia Teatro Lumbra de Animação. p. 193 Dissertação (Mestrado em Teatro). PPGT/UDESC. Florianópolis, 2011. OLIVEIRA, Fabiana Lazzari de. A pré-expressividade no trabalho do ator no Teatro de Sombras. 75 p. Trabalho de Conclusão de Curso. Graduação em Educação Artística - Habilitação em Artes Cênicas. CEART/UDESC. Florianópolis, 2012.

OLIVEIRA, Fabiana Lazzari de; BELTRAME, Valmor. A luz - elemento primordial no teatro de sombras. In: Urdimento. Florianópolis: PPGT/UDESC,v.2, nº 23, dezembro, 2014.

OSTROWER, Fayga. Criatividade e Processos de Criação. Petrópolis: Vozes, 2012.

VON FRANZ, M.-L. O Processo de Individuação. In: O Homem e seus Símbolos. JUNG, Carl. G. (org.). Rio de Janeiro: Nova Fronteira, 2008.

Recebido em março de 2019.

Aprovado em abril de 2019.

Publicado em junho de 2019. 